\title{
РАЗДЕЛЕНИЕ ПОЛИМЕРНОГО ПРОСТАГЛАНДИНА ПГВ И ОПРЕДЕЛЕНИЕ МОЛЕКУЛЯРНОЙ МАССЫ ОЛИГОМЕРОВ
}

Олигомерное соединение ПГВ 15-дегидро-ПГВ 1 по присоединению Михаеля щелочным катализатором, защищает ста́реющие митохондрии от гипотонической и термической деградации in vitro $\left[{ }^{1-3}\right]$ и является сильным ионофором $\mathrm{Ca}^{2+}\left[{ }^{4}\right]$. Кроме того, in vivo показано, что ПГВ ${ }_{x}$ защищает миокард и головной мозг при гипоксиальных инсультах $[5,6]$. Наивысшей активностью обладают олигомеры со средней молекулярной массой 2200-2500 (6-7 мономерных единиц) [ $\left.{ }^{7}\right]$. Однако разделение олигомеров с помощью гель-хроматографии на сефадексе LH-20 органическими элюентами нельзя считать удовлетворительным, поскольку получить кривую элюирования с дискретными максимумами не удалось [']. В связи с

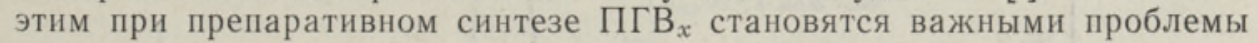
разделения продуктов полимеризации и определения их молекулярных мacc.

\section{Синтез ПГГВ}

Щелочную деградацию биосинтетического ПГЕ дили по методике $\left[{ }^{8}\right]$, образовавшиеся ПГВ 1 (6,97 ммоля) этерифицировали диазометаном. Для окисления гидроксильной группы в (-цепи ПГВ ${ }_{1}$ использовали пиридин хлорохромовокислый []. После хроматографирования продуктов окисления на силикагеле Л 40/100 мкм фирмы «Lachema» (ЧССР) (бензол и ацетон 100:5) получили 5,93 ммоля

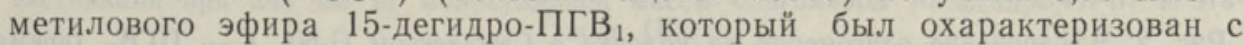
помощью УФ- и $\mathrm{C}^{13}$ ЯМР-спектроскопии. Синтез ПГВ $x$ и выделение его из реакционной смеси проводили по методике ['], но в целях увеличения доли ди-, три- и тетрамеров в конечном продукте время полимеризации сокращали до 15 мин.

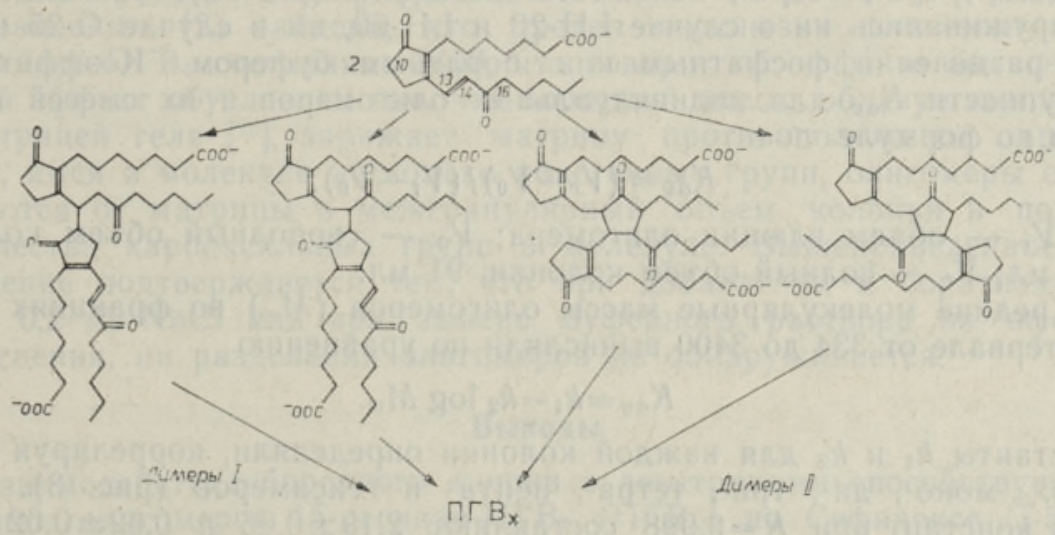

Рис. 1. Образование димеров 15-дегидро-ПГВ 
При полимеризации 15-дегидро-ПГВ 1 щелочным катализатором образуется два типа димеров в равных соотношениях [10] (рис. 1), так как вероятность образования карбанионов у С-10 и С-16 одинакова. Кроме того, в результате присоединения карбаниона к двойной св'язи у C-13 и у C-14 образуется по два изомера у димеров обоих типов ['1].

\section{Разделение олигомеров}

Для разделения продуктов полимеризации использовали пять гельносителей: Сефадексы LH-20, LH-60, G-25, G-50, G-75 фирмы «Pharmacia» (Швеция) и установку гель-хроматографии LKB (Швеция), включающей насос «Varioperpex», коллектор фракций «Redi Rac» и УФ-детектор «Uvicord III» при 254 нм с двухканальным самописцем. Колонки $(96 \times 1,1$ см) с LH-20 и LH-60 элюнровали метанолом со скоростью 10 мл/ч, а с G-25, G-50 и G-75 50 мМ боратным и фосфатным буферными растворами при $\mathrm{pH}$ 9. Фракции отбирали через каждые 1,5 мл элюирования. Разделяемые смеси олигомеров (2 мг/мл) в метаноле или 50 мМ буферном растворе при $\mathrm{pH} 9$, объемы которых не превышали $1 \%$ объема колонки, наносили в колонку автоматической пипеткой. Для приготовления элюентов использовали свежеперегнанный метанол, бидистиллят воды и реактивы.

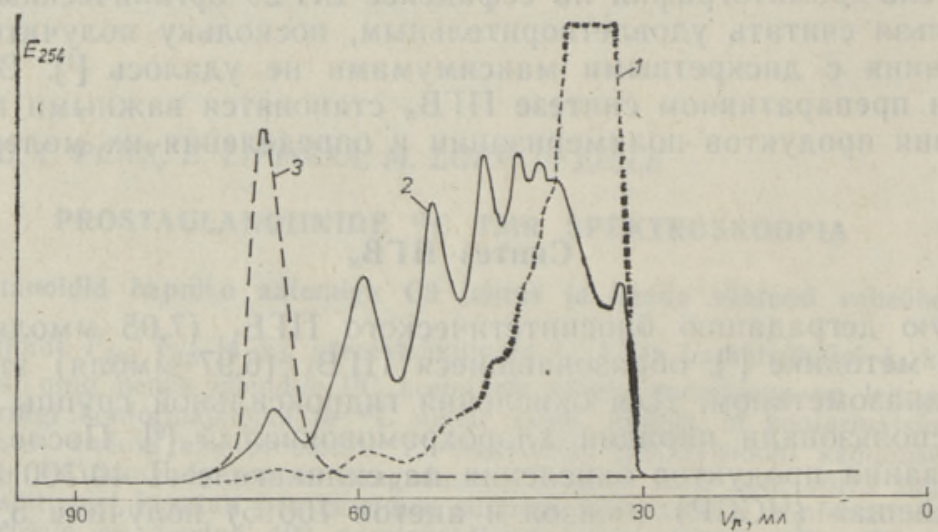

Рнс. 2. Элюнрование олигомеров на колонке с Сефадексом G-50: $1-$ ПГВ $\boldsymbol{x}$ (время полимеризации 4 ч), $2-$ ПГВ ${ }_{x}$ (время полимеризации 15 мнн), $3-15$-дегидро-ПГВ

Наилучшее разделение олигомеров 15-дегидро-ПГВ 1 достигалось на Сефадексе G-50 боратным буфером. В этом случае удалось выделить пики ди-, три-, тетра-, пента- и гексамеров (рис. 2). Такие пики не обнаруживались ни в случае LH-20 и LH-60, ни в случае G-25 и G-75 при разделении фосфатным или боратным буфером. Коэффициенты доступности $K_{a v}$ для индивидуальных олигомеров и их смесей вычисляли по формуле

$$
K_{a v}=\left(V_{r}-V_{0}\right) /\left(V_{t}-V_{0}\right) ;
$$

где $V_{r}$ - объем элюции олигомера; $V_{0}-$ свободный объем колонки, 31,2 мл; $V_{t}$ - полный объем колонки, 91 мл.

Средние молекулярные массы олигомеров $\left(M_{w}\right)$ во фракциях по $V_{r}$ в интервале от 334 до 3400 вычисляли по уравнению

$$
K_{a v}=k_{1}-k_{2} \log M_{w} .
$$

Константы $k_{1}$ и $k_{2}$ для каждой колонки определяли, коррелируя $K_{a v}$ и $\log M_{w}$ моно-, ди-, три-, тетра-, пента- и гексамеров (рис. 3). Величины констант при $R=0,998$ составляют $2,19 \pm 0,06$ и $0,62 \pm 0,02$ соответственно. 
Дляя определения коэффициента молярной экстинкции при 243 нм $\left(\varepsilon_{243}\right)$ фракции олигомеров подкисляли до $\mathrm{pH} 3$, экстрагировали этилацетатом и выпаривали. Затем фракции взвешивали и растворяли в этаноле. Зависимость $\varepsilon_{243}$ от молекулярной массы (рис. 4) носит нелинейный характер, что может быть обусловлено частичной экранизацией хромофорных группировок в молекуле олигомера. Эту возможность учитывали при определении концентрации олигомеров спектрофотомётрическим методом.

После хроматографирования 25 мг продукта полимеризации

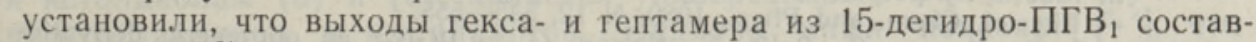
ляли 4 и $6 \%$ соответственно.
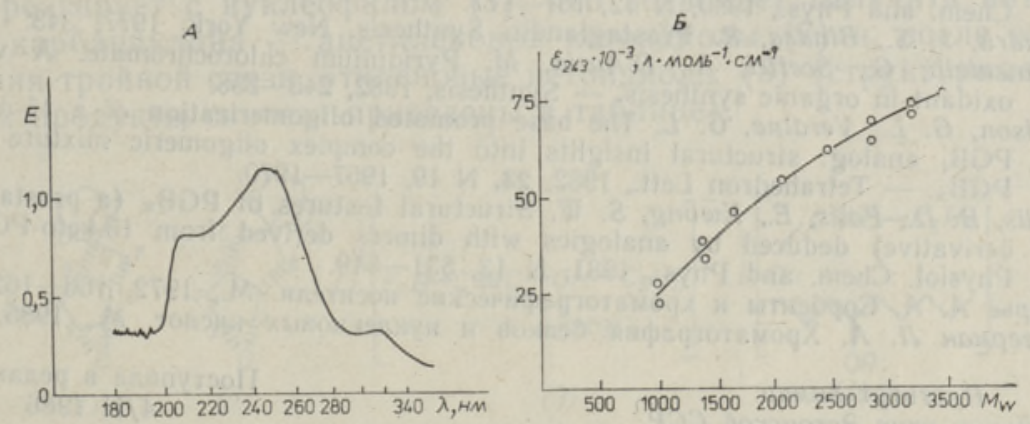

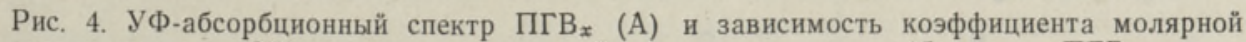
экстинкции при 243 нм от молекулярной массы олигомеров 15-дегидро-ПГВ в этаноле (Б).

\section{Обсуждение}

Разделение олигомеров ПГВ ко неожиданным, так как этот гель предусмотрен для фракционирования декстранов с молекулярными весами от 500 до 10000 [12]. Однако по уравнению (2) найдено, что предел эксклюзии для олигомеров 15 -дегидро-ПГВ 1 составляет 3400 , что говорит об эффекте вытеснения. Такой эффект обусловлен тем, что боратный анион, образуя комплексы с матрицей геля $\left[{ }^{13}\right]$, заряжает матрицу противоположным зарядом. Итак, имея в молекуле несколько ионогенных групп, олигомеры отталкиваются от матрицы в межгранулярный объем колонки в порядке количества карбоксильных групп в молекуле. Вышеприведенное рассуждение подтверждается тем, что при добавлении к боратному буферу $0,2 \mathrm{M} \mathrm{NaCl}$ или при замене буферного раствора ни эффекта вытеснения, ни разделения олигомеров не обнаруживается.

\section{Выводы}

1. Взаимодействие боратного аниона с декстранами способствует разделению олигомеров 15-дегидро-ПГВ ${ }_{1}$ (ПГВ ${ }_{x}$ ) на Сефадексе G-50 боратным буфером при $\mathrm{pH} 9$. 
2. В ходе разделения ПГВ $x$ можно определить молекулярные массы олигомеров в пределах от 334 до 3400 при их количестве менее чем 0,5 мг.

\section{ЛИТЕРАТ УРА}

1. Polis, B.-D., Kwong, S., Polis, E., Nelson, G., Shmukler, H. W. Studies on PGB a polymeric derivative of prostaglandin $B_{1}$. 1. Synthesis and purification of $\mathrm{PGB}_{x}$. - Physiol. Chem. and Phys., 1979, N 11, 109-123.

2. Shmukler, H. W., Zawryt, M. G., Soffer, E. F., Polis, E., Feely, W. M., Kwong, S. W., Cope, $F$. W. Studies on the mechanism of mitochondrial protection by polymeric prostaglandin $\mathrm{PGB}_{x}$. - Physiol. Chem. and Phys., 1982, N 14, 471-486.

3. Shmukler, H. W., Soffer, E., Zaweryt, M. G., Polis, E., Feely, W. M., Kwong, S. W., Cope, F. W. Mechanism of polymeric prostaglandin $\mathrm{PGB}_{x}$ for in vitro stabilization of rat liver mitochondrial oxidative phosphorylation. - Physiol. Chem. and Phys., 1982, N 14, 445-469.

4. Ohnishi, S. T., Devlin, T. M. Calcium ionophore activity of a prostaglandin $\mathrm{B}_{1}$ derivative $\left(\mathrm{PGB}_{x}\right)$ - - Biochem. Biophys. Res. Communs, 1979, 89, 240-245.

5. Polis, E., Cope, F. W. Polymeric prostaglandin $\mathrm{PGB}_{x}$ and other prostaglandin polymers prolong survival of the heart of the hypoxic mouse. - Aviation, Space and Environ. Med., 1983, 54, 420-424.

6. Kolata, R. J., Polis, B. D. Facilitation of recovery from ischemic brain damage in rabbits by polymeric prostaglandin $\mathrm{PGB}_{x}$, a mitochondrial protective agent. - Physiol. Chem. and Phys., 1980, N 12, 545-555.

7. Polis, B. D., Kwong, S., Polis, E., Nelson, G. L. PGB : an oligomeric derivative of prostaglandin $\mathrm{B}_{1}$ : physical, chemical and spectral properties. - Physiol. Chem. and Phys., 1980, N 12, 167-177.

8. Bindra, J. S., Bindra, R. Prostaglandin Synthesis. New York, 1977, 343.

9. Piancatelli, G., Scettri, A., D'Auria, M. Pyridinium chlorochromate. A versatile oxidant in organic synthesis. - Synthesis, 1982, 245-258.

10. Nelson, G. L., Verdine, G. L. The base promoted oligomerization of a 15-dehydro$\mathrm{PGB}_{1}$ analog: structural insights into the complex oligomeric mixture termed $\mathrm{PGB}_{x}$. - Tetrahedron Lett., 1982, 23, N 19, 1967-1970.

11. Polis, B. D., Polis, E., Kwong, S. W. Structural features of $\mathrm{PGB}_{x}$ (a prostaglandin derivative) deduced by analogies with dimers derived from 15-keto-PGB $\mathrm{PG}_{1}$ - Physiol. Chem. and Phys., 1981, N 13, 531-549.

12. Лурье A. А. Сорбенты и хроматографические носители. М., 1972, $160-162$.

13. Остерман Л. А. Хроматография белков и нукленновых кнслот. М., 1985, 117.

Институт химаи

Академии наук Эстонской ССР
Поступила в редакцию 4/II 1986

\section{MARTIN, Reet VIIDEMAA, N. SAMEL, O. LILLE}

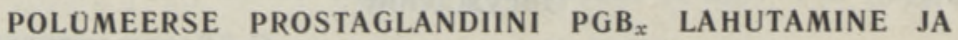 MOLEKULMASSI MAARAMINE}

On sünteesitud füsioloogiliselt aktiivne, polümeerne prostaglandiin $\mathrm{PGB}_{x}$ üle 15-dehüdro$\mathrm{PGB}_{1}$, lähtudes biosünteetilisest $\mathrm{PGB}_{1}$-st. $\mathrm{PGB}_{x}$ aktiivsed fraktsioonid eraldati polümeeride segust geelkromatograafia abil Sephadex G-50 kolonnis $50 \mathrm{mM}$ boraatpuhvriga $\mathrm{pH} 9$ juures. Leiti, et füsioloogiliselt aktiivseid oligomeere (heksa- ja heptameere) tekib vastavalt $4 \mathrm{ja} 6 \%$, lähtudes 15-dehüdro- $\mathrm{PGB}_{1}$-st. Oligomeeride molekulmassid vahemikus 334 kuni 3400 määrati väljumismahtude järgi eelnevalt kalibreeritud kolonni abil.

\section{MARTIN, Reet VIIDEMAA, N. SAMEL, O. LILLE}

\section{SEPARATION AND MOLECULAR WEIGHT DETERMINATION OF POLYMERIC PROSTAGLANDIN PGB $x$}

Synthesis of biologically active prostaglandin $\mathrm{PGB}_{x}$, an oligomeric derivative of 15 dehydro-PGB $\mathrm{PG}_{1}$, was performed. Separation of active components from the polymerization mixture by gel chromatography on Sephadex G-50 with $50 \mathrm{mM}$ borate buffer, $\mathrm{pH} 9$, was successful. The yield of biologically active hexa- and heptamers was 4 and 6 per cent, respectively. The molecular weights of oligomers within the range of $334-3400$ were determined by their elution volumes from the precalibred column. 